\title{
Quake after-effects
}

\author{
How the Earth's crust - rather than just buildings or humans - responds to the violent shaking of \\ an earthquake has been observed for centuries. Nevertheless, the wide range of geological impacts \\ continues to surprise.
}

In 1835, during his voyage on the HMS Beagle, Charles Darwin experienced a large earthquake that occurred near Concepción, Chile. Although saddened by the extent of the destruction in the town, Darwin was also intrigued by the diversity of natural spectacles that occurred in the wake of the violent ground motions: 'at the same hour when the whole country around Concepcion was permanently elevated, a train of volcanoes situated in the Andes, in front of Chiloe, instantaneously spouted out a dark column of smoke [...] We thus see a permanent elevation of the land, renewed activity through habitual vents, and a submarine outburst, forming parts of one great phenomenon.' ${ }^{\text {' Our }}$ understanding of the variety of responses of Earth's crust to large earthquakes continues to expand. A web focus published online with this issue (http://www.nature.com/ ngeo/focus/shaken-crust/index.html) explores some of these responses.

175 years after Darwin's visit to Chile, and in virtually the same location, the magnitude 8.8 Maule earthquake again left its mark on volcanic systems in the nearby Andes mountain range. Although the shaking on this occasion seemingly failed to trigger any eruptions, numerous volcanoes in the region sank by several centimetres almost immediately after the quake $^{2}$. Volcanoes in Japan, too, sank by similar amounts following the devastating 2011 Tohoku-Oki earthquake ${ }^{3,4}$. The precise cause of the sinking - escape of hydrothermal fluids or excessive subsidence of the hot, weak magma reservoirs as the tectonic plates rebounded - is still debated $^{5}$, but the remarkable similarities between the observations from Chile and Japan imply that quake-induced volcanic subsidence could be a common occurrence worldwide.

In addition to the spouting Andean volcanoes, Darwin's colleague, Captain Robert Fitz-Roy, observed a more subdued response to the Concepción quake. A potent, sulphurous smell bubbled up from the ocean following the submarine outburst, which Darwin attributed to a stir-up of decomposing organic matter

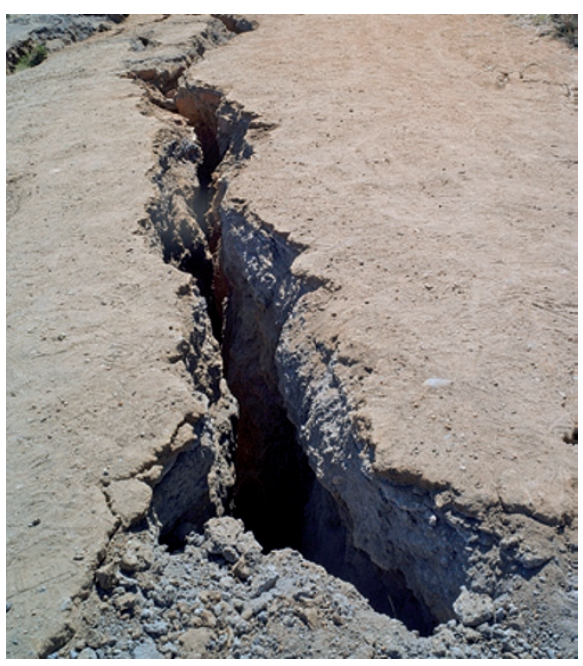

discussed as one of two possible alternative triggers for the devastating Lusi mud eruption in east Java, Indonesia. The mud volcano began erupting great volumes of torrid mud that submerged numerous villages and led to the evacuation of tens of thousands of people. The eruption is ongoing and may continue for decades to come. The Yogyakarta earthquake occurred just two days before the mud eruption, but any link was initially ruled out because the time delay between the quake and eruption onset seemed to be too long and the quake epicentre was so far off that the passing seismic waves should have been too weak to trigger such a violent response in the mud. Blame was instead put on an oil company drilling nearby. A Letter in this issue shows that the unusual, curved geometry of rocks surrounding the mud reservoir at Lusi could have amplified and focussed the effects of the passing seismic waves, generating sufficient stresses to liquefy and liberate mud in the reservoir ${ }^{7}$. The mud eruption could have been a natural response to an earthquake after all.

As Darwin observed during his time on the sea bed. A Letter in this issue also reports a seafloor response to a strong earthquake 6 . In this case, a quake in 1945 seems to have disturbed fragile gas hydrates trapped within sediments in the Arabian Sea, but the full extent of the seafloor response had gone undetected for almost 70 years. Seismic images and geochemical analyses now show that the magnitude 8.1 earthquake - the largest ever reported for the Arabian Sea - may have fractured sediments that held stores of hydrocarbons. About $3.26 \times 10^{8} \mathrm{~mol}$ of methane - a potent greenhouse gas - may have escaped in the decades following the quake and some could have reached the atmosphere. If quake-triggered release of methane is common, it could provide a significant contribution to the global carbon budget.

Some potential earthquake impacts on the crust are, however, so difficult to track that we may never be entirely sure of exact cause and effect. The Yogyakarta earthquake in 2006 has, for example, been in South America, the effects of large earthquakes go beyond the immediate shaking that can flatten entire towns. Earthquakes can continue to have devastating effects over many decades, triggering long-lived mud flows, elevating the risk of landslides in mountainous regions ${ }^{8}$ and prompting methane release that could impact the planet's climate. Given the potential societal impacts, these longer-term triggered events should be incorporated into our seismichazard response.

\footnotetext{
References

1. Darwin, C. R. The Voyage of the Beagle: Journal and Remarks 1832-1836 Ch. 16, 380 (Henry Colburn, 1839); http://darwin-online.org.uk

2. Pritchard, M. E., Jay, J. A., Aron, F., Henderson, S. T. \& Lara, L. E. Nature Geosci. 6, 632-636 (2013).

3. Takada, Y. \& Fukushima, Y. Nature Geosci. 6, 637-641 (2013).

4. Ozawa, T. \& Fujita, E. J. Geophys. Res. 118, 390-405 (2013).

5. Jónsson, S. Nature Geosci. 6, 591-592 (2013).

6. Fischer, D. et al. Nature Geosci. 6, 647-651 (2013).

7. Lupi, M., Saenger, E. H., Fuchs, F. \& Miller, S. A. Nature Geosci. 6, 642-646 (2013).

8. Huang, R. \& Fan, X. Nature Geosci. 6, 325-326 (2013)
} 